\title{
A NOTE ON THE SEMILOCAL CONVERGENCE OF CHEBYSHEV'S METHOD
}

\author{
MANUEL A. DILONÉ凶 ${ }^{\otimes}$ MARTÍN GARCÍA-OLIVO and JOSÉ M. GUTIÉRREZ
}

(Received 7 June 2012; accepted 14 July 2012; first published online 15 October 2012)

\begin{abstract}
In this paper we develop a Kantorovich-like theory for Chebyshev's method, a well-known iterative method for solving nonlinear equations in Banach spaces. We improve the results obtained previously by considering Chebyshev's method as an element of a family of iterative processes.
\end{abstract}

2010 Mathematics subject classification: primary 65J15; secondary 47H10.

Keywords and phrases: nonlinear equations, iterative methods, Chebyshev's method, Kantorovich theory.

\section{Introduction}

Chebyshev's method is a well-known iterative process used to solve nonlinear equations. It is named after the famous Russian mathematician Pafnuty L. Chebyshev (1821-1894), who introduced an algorithmic approach for solving algebraic equations $y=f(x)$. This process was based on Newton's method and on the expansion as a power series of the inverse of the function $f$. Chebyshev presented his method in a paper entitled 'The calculation of the roots of an equation', written when he was a student in 1840-1841. He was awarded a silver medal by the Department of Physics and Mathematics of the University of Moscow, where he was studying [22].

For real or complex-valued functions Chebyshev's method can be written as

$$
t_{n+1}=t_{n}-\left(1+\frac{1}{2} L_{f}\left(t_{n}\right)\right) \frac{f\left(t_{n}\right)}{f^{\prime}\left(t_{n}\right)}, \quad n=0,1,2, \ldots,
$$

where

$$
L_{f}(t)=\frac{f(t) f^{\prime \prime}(t)}{f^{\prime}(t)^{2}} .
$$

The method (1.1) goes under various names [22]. For instance, it is called Euler's method in $[6,17,22]$, the method of tangent parabolas in [2], the super-Newton method

The research of the third author is partially supported by a grant of the Spanish Ministry of Science and Innovation (Ref. MTM2011-28636-C02-01).

(C) 2012 Australian Mathematical Publishing Association Inc. 0004-9727/2012 \$16.00 
in [18], the Euler-Chebyshev method in [17, 22], Schröder's method in [12], and the inverse quadratic interpolation method in $[8,11]$. However, in the Russian literature the method is attributed to Chebyshev and this is nowadays accepted by many authors (see [1, 4, 7, 21], for instance).

Chebyshev's method can be generalised for solving nonlinear systems of equations or, more generally, for solving operator equations defined in Banach spaces [1, 3, 4, 9, 13, 19]. In this framework, let $X$ and $Y$ be two Banach spaces and let $F: \Omega \subseteq X \rightarrow Y$ be a nonlinear twice Fréchet differentiable operator defined in an open convex domain $\Omega$. Then Chebyshev's method for solving the operator equation

$$
F(x)=0
$$

can be written in the form

$$
x_{n+1}=x_{n}-\left(I+\frac{1}{2} L_{F}\left(x_{n}\right)\right) F^{\prime}\left(x_{n}\right)^{-1} F\left(x_{n}\right), \quad n=0,1,2, \ldots,
$$

where $I$ is the identity operator on $X$ and $L_{F}(x)$ is the linear operator formally defined as follows:

$$
L_{F}(x)=F^{\prime}(x)^{-1} F^{\prime \prime}(x) F^{\prime}(x)^{-1} F(x) .
$$

This operator and its relationship with Newton's method were studied in [14]. In [13] the method is studied as a part of the family of iterative processes

$$
x_{n+1}=x_{n}-\left(I+\frac{1}{2} L_{F}\left(x_{n}\right)\left(I-\alpha L_{F}\left(x_{n}\right)\right)^{-1}\right) F^{\prime}\left(x_{n}\right)^{-1} F\left(x_{n}\right), \quad n=0,1,2, \ldots,
$$

which includes, together with Chebyshev's method $(\alpha=0)$ other famous iterative methods such as the Halley $(\alpha=1 / 2)$ or super-Halley $(\alpha=1)$. In the latter paper a unifying theory for methods of this kind is developed; however, there is a serious omission. Only the quadratic order of convergence is guaranteed for the methods with $0 \leq \alpha<1 / 2$ although it is well known that Chebyshev's method is cubically convergent [22].

In this paper we particularise our study to Chebyshev's method (1.4) in Banach spaces, and we provide a semilocal convergence theorem that guarantees the third order of convergence. Thus, we improve the result given in [13]. In recent papers (see $[4,5,7,15,20]$ ) we can find theorems on the convergence of Chebyshev's method that differ both in their assumptions and their results. In this paper we state a Kantorovich-like theorem for Chebyshev's method along the same lines followed by Zheng and Robbie [24] for Halley's method.

\section{Some preliminary results}

In the general framework of Kantorovich theory [16], to prove the semilocal convergence of a third-order iterative method in Banach space (see [13, 23, 24], for instance), we assume throughout this paper the following conditions.

(i) There exists a point $x_{0} \in \Omega$ where the linear operator $\Gamma_{0}=F^{\prime}\left(x_{0}\right)^{-1}$ is defined.

(ii) $\left\|\Gamma_{0}\left(F^{\prime \prime}(x)-F^{\prime \prime}(y)\right)\right\| \leq k\|x-y\|, x, y \in \Omega, k>0$. 
(iii) $\left\|\Gamma_{0} F\left(x_{0}\right)\right\| \leq a,\left\|\Gamma_{0} F^{\prime \prime}\left(x_{0}\right)\right\| \leq b$.

(iv) The equation

$$
p(t)=\frac{k}{6} t^{3}+\frac{b}{2} t^{2}-t+a=0
$$

has one negative root and two positive roots $r_{1}$ and $r_{2}\left(r_{1} \leq r_{2}\right)$.

(v) $S=\left\{x:\left\|x-x_{0}\right\| \leq r_{1}\right\} \subseteq \Omega$.

REMARK 2.1. The following conditions are equivalent to condition (iv). Both of them can be deduced just by assuming $p^{\prime}(\rho) \leq 0$, where $\rho$ is the local minimum of the polynomial $p(t)$ defined in $(2.1)$.

(1) $a \leq\left(b^{2}+4 k-b \sqrt{b^{2}+2 k}\right) /\left(3 k\left(b+\sqrt{b^{2}+2 k}\right)\right)$.

(2) $9 k^{2} a^{2}+18 a b k+6 a b^{3} \leq 3 b^{2}+8 k$.

REMARK 2.2. Notice that the polynomial $p(t)$ defined in (2.1) has in addition a negative root. We denote it as $-r_{0}$ with $r_{0}>0$.

Lemma 2.3. Let us define the scalar sequence $\left\{t_{n}\right\}$ by

$$
t_{0}=0, \quad t_{n+1}=H\left(t_{n}\right)=t_{n}-\left(1+\frac{1}{2} L_{p}\left(t_{n}\right)\right) \frac{p\left(t_{n}\right)}{p^{\prime}\left(t_{n}\right)}, \quad n \geq 0,
$$

where $p(t)$ is the polynomial defined in (2.1). Then $\left\{t_{n}\right\}$ is monotonic increasing and convergent to $r_{1}$, the smallest positive zero of $p(t)$.

Proof. As $p\left(t_{0}\right)=a>0$, we know that $t_{0}<r_{1}$. By the mean value theorem,

$$
t_{1}-r_{1}=H^{\prime}\left(s_{0}\right)\left(t_{0}-r_{1}\right)
$$

for some $s_{0} \in\left(t_{0}, r_{1}\right)$. Note that

$$
H^{\prime}(t)=\frac{L_{p^{\prime}}(t)^{2}}{2\left(1-L_{p^{\prime}}(t)\right)^{2}}\left(1-L_{p}(t)\right)^{2}\left(3-L_{p^{\prime}}(t)\right),
$$

where $L_{p}(t)$ is defined in (1.2) and $L_{p^{\prime}}(t)$ is defined as

$$
L_{p^{\prime}}(t)=\frac{p^{\prime}(t) p^{\prime \prime \prime}(t)}{p^{\prime \prime}(t)^{2}}
$$

Taking into account that $p(t)$ is positive, decreasing and convex on the interval $\left[0, r_{1}\right]$, and that $H^{\prime}(t) \geq 0$ on $\left[0, r_{1}\right]$, it follows that $t_{1} \leq r_{1}$.

On the other hand,

$$
t_{1}-t_{0}=-\frac{p\left(t_{0}\right)}{p^{\prime}\left(t_{0}\right)}\left(1+\frac{1}{2} L_{p}\left(t_{0}\right)\right) \geq 0
$$

Then we obtain $t_{n} \leq r_{1}$ and $t_{n-1} \geq t_{n}$ for all $n \geq 1$ by mathematical induction, since $\left(t_{n-1}, r_{1}\right) \subset\left(t_{0}, r_{1}\right)$.

So the sequence (2.2) is convergent to $r_{1}$. 
Lemma 2.4. Let $\rho$ be the only positive root of $p^{\prime}(t)=0$, where $p(t)$ is the polynomial defined in (2.1). Under the conditions (i)-(v) previously defined, if $\left\|x-x_{0}\right\| \leq \rho$, then the inverse $F^{\prime}(x)^{-1}$ exists and

$$
\begin{aligned}
& \left\|F^{\prime}(x)^{-1} F^{\prime}\left(x_{0}\right)\right\| \leq-\frac{1}{p^{\prime}\left(\left\|x-x_{0}\right\|\right)}, \\
& \left\|F^{\prime}\left(x_{0}\right)^{-1} F^{\prime \prime}(x)\right\| \leq p^{\prime \prime}\left(\left\|x-x_{0}\right\|\right) .
\end{aligned}
$$

Proof. Note that

$$
p^{\prime}(t)=\frac{k}{2} t^{2}+b t-1
$$

has two real roots given by

$$
t_{+}=\frac{-b+\sqrt{b^{2}-2 k}}{k}, \quad t_{-}=\frac{-b-\sqrt{b^{2}-2 k}}{k} .
$$

Then, when $\left\|x-x_{0}\right\|<t_{+}$, it follows that

$$
p^{\prime}\left(\left\|x-x_{0}\right\|\right)=\frac{k}{2}\left\|x-x_{0}\right\|^{2}+b\left\|x-x_{0}\right\|-1<0 .
$$

Thus, under the conditions of the theorem,

$$
\begin{aligned}
& \left\|f^{\prime}\left(x_{0}\right)^{-1} f^{\prime \prime}\left(x_{0}\right)\left(x-x_{0}\right)+\int_{0}^{1} f^{\prime}\left(x_{0}\right)^{-1}\left(f^{\prime \prime}\left(x_{0}+t\left(x-x_{0}\right)\right)-f^{\prime \prime}\left(x_{0}\right)\right) d t\left(x-x_{0}\right)\right\| \\
& \quad \leq b\left\|x-x_{0}\right\|+\frac{k}{2}\left\|x-x_{0}\right\|^{2}<1 .
\end{aligned}
$$

Considering the mean value theorem, it follows that

$$
f^{\prime}(x)=f^{\prime}\left(x_{0}\right)+\int_{0}^{1} f^{\prime \prime}\left(x_{0}+t\left(x-x_{0}\right)\right) d t\left(x-x_{0}\right),
$$

where

$$
\begin{aligned}
f^{\prime}\left(x_{0}\right)^{-1} f^{\prime}(x)=I & +f^{\prime}\left(x_{0}\right)^{-1} f^{\prime \prime}\left(x_{0}\right)\left(x-x_{0}\right) \\
& +\int_{0}^{1} f^{\prime}\left(x_{0}\right)^{-1}\left(f^{\prime \prime}\left(x_{0}+t\left(x-x_{0}\right)\right)-f^{\prime \prime}\left(x_{0}\right)\right) d t\left(x-x_{0}\right) .
\end{aligned}
$$

It follows that, by Neumann's lemma, the inverse of $f^{\prime}\left(x_{0}\right)^{-1} f^{\prime}(x)$ exists and equals $f^{\prime}(x)^{-1} f^{\prime}\left(x_{0}\right)$. Then

$$
\left\|f^{\prime}(x)^{-1} f^{\prime}\left(x_{0}\right)\right\| \leq \frac{1}{1-b\left\|x-x_{0}\right\|-\frac{k}{2}\left\|x-x_{0}\right\|^{2}}=\frac{1}{p^{\prime}(t)}
$$

and

$$
\begin{aligned}
\left\|f^{\prime}\left(x_{0}\right)^{-1} f^{\prime \prime}(x)\right\| & \leq\left\|f^{\prime}\left(x_{0}\right)^{-1} f^{\prime \prime}\left(x_{0}\right)\right\|+\left\|f^{\prime}\left(x_{0}\right)^{-1}\left[f^{\prime \prime}\left(x_{0}\right)-f^{\prime \prime}(x)\right]\right\| \\
& \leq b+k\left\|x-x_{0}\right\|=p^{\prime \prime}\left(\left\|x-x_{0}\right\|\right),
\end{aligned}
$$

and the proof of the lemma is complete. 
LeMma 2.5. With the same notation and assumptions as above, we can write $F\left(x_{n+1}\right)$ in the following way:

$$
F\left(x_{n+1}\right)=\frac{1}{8} F^{\prime \prime}\left(x_{n}\right) y_{n}^{2}+\frac{1}{2} F^{\prime \prime}\left(x_{n}\right) \Gamma_{n} F\left(x_{n}\right) y_{n}+\int_{x_{n}}^{x_{n+1}}\left(F^{\prime \prime}(x)-F^{\prime \prime}\left(x_{n}\right)\right)\left(x_{n+1}-x\right) d x,
$$

where $\Gamma_{n}=F^{\prime}\left(x_{n}\right)^{-1}$ and $y_{n}=L_{F}\left(x_{n}\right) \Gamma_{n} F\left(x_{n}\right)$.

Proof. By Taylor's formula, and taking into account condition (2), we deduce that

$$
\begin{aligned}
F\left(x_{n+1}\right)= & F\left(x_{n}\right)+F^{\prime}\left(x_{n}\right)\left(x_{n+1}-x_{n}\right)+\frac{1}{2} F^{\prime \prime}\left(x_{n}\right)\left(x_{n+1}-x_{n}\right)^{2} \\
& +\int_{x_{n}}^{x_{n+1}}\left(F^{\prime \prime}(x)-F^{\prime \prime}\left(x_{n}\right)\right)\left(x_{n+1}-x\right) d x \\
=- & \frac{1}{2} F^{\prime \prime}\left(x_{n}\right) \Gamma_{n} F\left(x_{n}\right) \Gamma_{n} F\left(x_{n}\right)+\frac{1}{2} F^{\prime \prime}\left(x_{n}\right)\left(\Gamma_{n} F\left(x_{n}\right)\right)^{2} \\
& +\frac{1}{8} F^{\prime \prime}\left(x_{n}\right) y_{n}^{2}+\frac{1}{2} F^{\prime \prime}\left(x_{n}\right) \Gamma_{n} F\left(x_{n}\right) y_{n} \\
& +\int_{x_{n}}^{x_{n+1}}\left(F^{\prime \prime}(x)-F^{\prime \prime}\left(x_{n}\right)\right)\left(x_{n+1}-x\right) d x,
\end{aligned}
$$

and the result holds.

\section{Main results}

We are now in a position to prove the following Kantorovich-type theorems for Chebyshev's method (1.4).

THEOREM 3.1. Let us assume that conditions (i)-(v) introduced in the previous section hold. Then the sequence $\left\{x_{n}\right\}$ defined by Chebyshev's method (1.4) is well defined, remains in $S$ and converges to a solution $x^{*}$ of (1.3). In addition, the following error estimation is satisfied:

$$
\left\|x^{*}-x_{n}\right\| \leq r_{1}-t_{n},
$$

where $\left\{t_{n}\right\}$ is the sequence defined in (2.2), that is, Chebyshev's method applied to the polynomial $p(t)$ defined in (2.1), and $r_{1}$ is the smallest positive zero of $p(t)$.

Proof. Following [24], we have to prove that the following conditions are true for all nonnegative integers $n$ :

(1) $x_{n} \in S=\left\{x:\left\|x-x_{0}\right\| \leq r_{1}\right\}$;

(2) the inverse $\Gamma_{n}=F^{\prime}\left(x_{n}\right)^{-1}$ exists;

(3) $\left\|\Gamma_{0} F\left(x_{n}\right)\right\| \leq p\left(t_{n}\right)$;

(4) $\left\|\Gamma_{n} F^{\prime}\left(x_{0}\right)\right\| \leq-1 / p\left(t_{n}\right)$;

(5) $\left\|\Gamma_{0} F^{\prime \prime}\left(x_{n}\right)\right\| \leq p^{\prime \prime}\left(t_{n}\right)$;

(6) $\left\|x_{n+1}-x_{n}\right\| \leq t_{n+1}-t_{n}$. 
Firstly, notice that (6) is an immediate consequence of (1)-(5). Next, (i)-(v) guarantee that (1)-(5) are true for $n=0$. Let us assume now that (1)-(5) are true for $n \leq k$. Then (6) also holds and

$$
\left\|x_{k+1}-x_{0}\right\| \leq t_{k+1}-t_{0}<r_{1} \leq \rho .
$$

Consequently $x_{k+1} \in S$. From Lemma 2.4, $\Gamma_{k+1}=F^{\prime}\left(x_{k+1}\right)^{-1}$ also exists and (4) and (5) hold for $n=k+1$.

Now, from Lemma 2.5,

$$
\begin{aligned}
\left\|\Gamma_{0} F\left(x_{k+1}\right)\right\|= & \frac{1}{8}\left\|\Gamma_{0} F^{\prime \prime}\left(x_{k}\right) y_{k}^{2}\right\|+\frac{1}{2}\left\|\Gamma_{0} F^{\prime \prime}\left(x_{k}\right) \Gamma_{k} F\left(x_{k}\right) y_{k}\right\| \\
& \quad+\left\|\int_{0}^{1} \Gamma_{0}\left(F^{\prime \prime}\left(x_{k}+u\left(x_{n+1}-x_{k}\right)\right)-F^{\prime \prime}\left(x_{k}\right)\right)(1-u) d u\left(x_{k+1}-x_{k}\right)\right\| \\
\leq & \frac{1}{8} L_{p}\left(t_{k}\right)^{3} p\left(t_{k}\right)+\frac{1}{2} L_{p}\left(t_{k}\right)^{2} p\left(t_{k}\right)+\frac{k}{6}\left(t_{k+1}-t_{k}\right)^{3}=p\left(t_{k+1}\right) .
\end{aligned}
$$

Hence (3) is also true for $n=k+1$. Thus (1)-(5) hold for all $n \geq 0$ and, as a consequence, (6) holds too for all $n \geq 0$. As $\left\{t_{n}\right\}$ is a convergent sequence, (6) implies that $\left\{x_{n}\right\}$ is also convergent. Let us denote its limit by $x^{*}$. Letting $n \rightarrow \infty$ in (3), we deduce that $F\left(x^{*}\right)=0$, and then $x^{*}$ is a solution of (1.3). Finally, the error estimation can be deduced by recursively applying (6) so

$$
\left\|x_{n+j}-x_{n}\right\| \leq t_{n+j}-t_{n}, \quad j \geq 1
$$

and letting $j \rightarrow \infty$.

Kantorovich's theory [16] can be used not only to show the convergence of an iterative method, but simultaneously as an existence and uniqueness theory for nonlinear equations. In this regard, we can state the following result.

THEOREM 3.2. Let us assume that conditions $(i)-(v)$ introduced in the previous section hold. Then (1.3) has a solution $x^{*}$ that lies in the closed ball $B_{1}=\left\{x \in X:\left\|x-x_{0}\right\| r_{1}\right\} \subseteq$ $\Omega$ and is unique in the set $B_{2}=\left\{x \in X:\left\|x-x_{0}\right\| r_{2}\right\} \cap \Omega$, where $r_{1}$ and $r_{2}$ are the positive roots of the polynomial $p(t)$ defined in (2.1).

Proof. The fact that $x^{*} \in B_{1}$ follows directly by taking $n=0$ in (3.1). To show the uniqueness, we assume that there exists another solution $y^{*}$ of (1.3) in $B\left(x_{0}, r_{2}\right)$. Following [4, 10],

$$
0=F\left(y^{*}\right)-F\left(x^{*}\right)=\int_{0}^{1} F^{\prime}\left(x^{*}+t\left(y^{*}-x^{*}\right)\right) d t\left(y^{*}-x^{*}\right) .
$$


We prove that $\int_{0}^{1} F^{\prime}\left(x^{*}+t\left(y^{*}-x^{*}\right)\right) d t$ is invertible. Notice that

$$
\begin{aligned}
I- & \Gamma_{0} \int_{0}^{1} F^{\prime}\left(x^{*}+t\left(y^{*}-x^{*}\right)\right) d t \\
& =-\Gamma_{0} \int_{0}^{1} \int_{x_{0}}^{x^{*}+t\left(y^{*}-x^{*}\right)} F^{\prime \prime}(z) d z d t \\
& =-\Gamma_{0} \int_{0}^{1} \int_{x_{0}}^{x^{*}+t\left(y^{*}-x^{*}\right)}\left(F^{\prime \prime}\left(x_{0}\right)+\left(F^{\prime \prime}(z)-F^{\prime \prime}\left(x_{0}\right)\right)\right) d z d t,
\end{aligned}
$$

and then

$$
\left\|I-\Gamma_{0} \int_{0}^{1} F^{\prime}\left(x^{*}+t\left(y^{*}-x^{*}\right)\right) d t\right\| \leq \frac{k}{6} r_{2}^{2}+\left(\frac{k}{6} r_{1}+\frac{b}{2}\right)\left(r_{2}+r_{1}\right) .
$$

We need to prove that

$$
\frac{k}{6} r_{2}^{2}+\left(\frac{k}{6} r_{1}+\frac{b}{2}\right)\left(r_{2}+r_{1}\right)<1
$$

To do this, let us define the polynomial

$$
q(r)=\frac{k}{6} r^{2}+\left(\frac{k}{6} r_{1}+\frac{b}{2}\right) r+\left(\frac{k}{6} r_{1}^{2}+\frac{b}{2} r_{1}-1\right) .
$$

Observe that $q(0)<0$. Now, by using Cardano's formulas we have $r_{1}+r_{2}=r_{0}-$ $(3 b / k)$ and $r_{1} r_{2}=6 a / k r_{0}$ where $-r_{0}, r_{1}$ and $r_{2}$ are the roots of (2.1) Then $q\left(r_{2}\right)=$ $-p\left(-r_{0}\right) / r_{0}=0$ and (3.2) is fulfilled. Thus the proof is complete.

\section{References}

[1] S. Amat, S. Busquier, J. M. Gutiérrez and M. A. Hernández, 'On the global convergence of Chebyshev's iterative method', J. Comput. Appl. Math. 220 (2008), 17-21.

[2] I. K. Argyros, 'The convergence of a Halley-Chebysheff-type method under Newton-Kantorovich hypotheses', Appl. Math. Lett. 6 (1993), 71-74.

[3] I. K. Argyros, Convergence and Applications of Newton-Type Iterations (Springer, New York, 2008).

[4] I. K. Argyros and D. Chen, 'Results on Chebyshev method in Banach space', Proyecciones 12 (1993), 119-128.

[5] I. K. Argyros, J. A. Ezquerro, J. M. Gutiérrez, M. A. Hernández and S. Hilout, 'On the semilocal convergence of efficient Chebyshev-Secant-type methods', J. Comput. Appl. Math. 235 (2011), 3195-3206.

[6] E. Bodewig, 'Über das Eulersche Verfahren zur Auflösung numerischer Gleichungen', Comment. Math. Helv. 8 (1935), 1-4.

[7] V. Candela and A. Marquina, 'Recurrence relations for rational cubic methods II: The Chebyshev method', Computing 45 (1990), 113-130.

[8] D. Chen and I. K. Argyros, 'Results on Chebyshev method in Banach space', Proyecciones 12 (1993), 119-128.

[9] C. Chun, 'Some variants of Chebyshev-Halley methods free from second derivative', Appl. Math. Comput. 191 (2007), 193-198. 
[10] J. A. Ezquerro, J. M. Gutiérrez and M. A. Hernández, 'A construction procedure of iterative methods with cubical convergence', Appl. Math. Comput. 85 (1997), 181-199.

[11] W. Gander, 'On Halley's iteration method', Amer. Math. Monthly 92 (1985), 131-134.

[12] W. J. Gilbert, 'Generalizations of Newton's method', Fractals 9 (2001), 251-262.

[13] J. M. Gutiérrez and M. A. Hernández, 'A family of Chebyshev-Halley type methods in Banach spaces', Bull. Aust. Math. Soc. 55 (1997), 113-130.

[14] J. M. Gutiérrez, M. A. Hernández and M. A. Salanova, 'Accesibility of solutions by Newton's method', Int. J. Comput. Math. 57 (1995), 239-247.

[15] M. A. Hernández and M. A. Salanova, 'Modification of the Kantorovich assumptions for semilocal convergence of the Chebyshev method', J. Comput. Appl. Math. 126 (2000), 131-143.

[16] L. V. Kantorovich and G. P. Akilov, Functional Analysis (Pergamon Press, Oxford, 1982).

[17] N. Kjurkchiev, 'Initial approximations in Euler-Chebyshev's method', J. Comput. Appl. Math. 58 (1995), 233-236.

[18] K. Kneisl, 'Julia sets for the super-Newton method, Cauchy's method, and Halley's method', Chaos 11 (2001), 359-370.

[19] J. Kou, 'On Chebyshev-Halley with sixth-order convergence for solving nonlinear equations', Appl. Math. Comput. 190 (2007), 126-131.

[20] P. K. Parida and D. K. Gupta, 'Semilocal convergence of a family of third-order Chebyshev-type methods under a mild differentiability condition', J. Comput. Appl. Math. 87 (2010), 3330-3343.

[21] M. S. Petković, L. D. Petković and Y. D. Herceg, 'On Schröder's families of root-finding methods', J. Comput. Appl. Math. 233 (2010), 1755-1762.

[22] J. F. Traub, Iterative Methods for the Solution of Equations (Prentice Hall, Englewood Cliffs, NJ, 1964).

[23] T. Yamamoto, 'On the method of tangent hyperbolas in Banach spaces', J. Comput. Appl. Math. 21 (1988), 75-86.

[24] S. Zheng and D. Robbie, 'A note on the convergence of Halley's method for solving operator equations', J. Aust. Math. Soc. Ser. B 37 (1995), 16-25.

MANUEL A. DILONÉ, Dpto. de Investigación del ISFODOSU,

Santo Domingo, Dominican Republic

e-mail: dilonespinal@hotmail.es

MARTÍN GARCÍA-OLIVO, Politécnico Militar San Miguel Arcángel,

Santo Domingo, Dominican Republic

e-mail: martin1matdr@hotmail.com

JOSÉ M. GUTIÉRREZ, Dpto. de Matemáticas y Computación, Universidad de La Rioja, Logroño, Spain

e-mail: jmguti@unirioja.es 